\section{THE ROYAL SOCIETY OF MEDICINE.}

\author{
$B y$ J. KINGSTON BARTON, \\ M.R.C.P.(LOND.).
}

A MEDICAL, practitioner, after fifty years work in and near London, would like to draw attention to the very many advantages that should induce all young qualified men to seek election as Fellows of the Royal Society of Medicine.

(I) After paying his fee for being placed on the Medical Register, a qualified man can make no better investment than to get elected as a Fellow to the Royal Society of Medicine.

(2) By so doing he at once has tantamount to a London club, the most valuable part of which is its magnificent medical library. With the use of its reading rooms he can refer to every medical newspaper and periodical, saving thereby much expense if he is on the look-out for appointments, \&c., or he can devote his time to valuable study if he is reading for higher examinations. For although every hospital has its own good library, yet the extra hours that the reading rooms are open at the Royal Society of Medicine make it of extreme value to the young, to the middle-aged, and even to the old practitioners. The above should appeal strongly to any one living within fifty miles of London, as well as to the post-graduate men.

(3) The Proceedings of the Royal Society of Medicine are, in addition, a complete encyclopadia of all the most recent work and ideas in every branch of medicine and surgery, so that by reference to the index of the most recent year one can gain immediate information on any subject which is new or strange to any inquirer.

(4) An outstanding gain to the modern medical man, if he becomes a Fellow of the Royal Society of Medicine after his examinations are over, is that he need spend no more money on medical books.
In former years doctors had to spend vast sums of money on books, and even valuable books were a sheer waste of capital. In present days any book is almost out of date within a year of its publication, and so a large library of unsaleable books accumulates. The lending out rules of the Society's library prevent all this waste. It might here be remarked that older Fellows of the Society who probably have large numbers of medical books, which if sent to auction only bring in a few pence, might offer them in the first place to the library, to replace any of their much used books.

(5) In former years, soon after qualification we had to join various medical societies at subscriptions totalling much above the subscription to the present Royal Society of Medicine, and in this matter a good saving in annual expenses is made.

(6) Young specialists, living within fifty miles of London, would derive enormous advantages of filling up spare time in quickly reading up all home and foreigno advances in their subjects with the aid of the Society's rooms and the lending-library. Besides the advantages of the various clinical meetings with abundant cases, \&c., in much more agreeable surroundings than in the out-patient rooms of the hospitals.

Distant provincial men, on the provincial subscription, would also find these advantages an attraction. With the modern system of large number partnerships, each partner is expected to take up a speciality, and these men can thus be better able to keep up-to-date by the help of their Fellowship.

(7) During each session there are several very important meetings with full discussions where the leading men can be seen and heard, which many Fellows are glad to attend, and feel they are in the swim of affairs.

(8) There are more than 8,00o doctors in the London area, and 22,000 in the English Provinces, and total number of qualified men on the Register is over 55,000. 
One feels that at least 3,000 of these in the London area ought to be Fellows of the Society, and 6,000 or even more of the remainder would be well advised to become Fellows.

Careful perusal of the year's handbook of the Society will reveal many other advantages that each individual Fellow will soon recognize are at his command.

Copies of the Calendar of the Royal Society of Medicine, giving full particulars of the Society's activities, may be obtained from the Royal Society of Medicine or from the Fellowship of Medicine. It may be noted that both men and women in Great Britain and overseas are eligible to be elected Fellows of the Royal Society of Medicine.

\section{POST-GRADUATE NEWS.}

SIx Special Courses will be given during September.

Hospital for Consumption and Diseases of the Chest, Brompton.

A Course will be held from September 7 to September I2, occupying the whole of each day with lectures and demonstrations. The fee is $£ 33$ s.

\section{Bethlem Royal Hospital.}

From September 8 to October 3, a Course in Psychological Medicine will be given at the Bethlem Royal Hospital, Monks Orchard, Eden Park, Beckenham, Kent. The LectureDemonstrations will be given at I a.m., on Tuesdays and Saturdays, by Dr. Porter Phillips and the Medical Staff, and the best route to the Hospital is to travel by the Southern Railway to Eden Park Station. The fee is $€ \mathrm{I}$ Is.

\section{Infants Hospital, Vincent Square, S.W. I.}

An afternoon Course in Diseases of Infants will be held from September I $4_{4}$ to September 26. In addition to lectures and demonstrations at the Hospital, special visits will be made to the United Dairies Pasteurizing Plant at Willesden, to the Nursery Training School at Hampstead, and to the V.D. Centre, Holborn. The fee is $\ell_{3} 3$ s.

Central London Ophthalmic Hospital, Judd Street, W.C. I.

From September I $5_{5}$ to October 8 a Course in Ophthalmology will be held. Lecture-demonstrations will be given every afternoon, and in addition the practice of the Hospital will be open to post-graduates, and operations performed daily at 2 p.m. The fee is $£ 33$ s.

Westminster Hospital.

A "refresher" Course will be given from September I4 to September 26, occupying the whole of each day from ro.30 a.m. to 5.30 p.m. with lectures, demonstrations and operations. The Course is open only to men post-graduates, and is especially suitable for Insurance Practitioners. The fee is $£ 5$ 5s. for two weeks, or $£ 33$ s. for eithero week.

Mctropolitan Hospital, Kingsland Road.

Following immediately after the above Course, a similar one will be given at the Metropolitan Hospital, Kingsland Road, from September 28 to October ro. From io.30 a.m. to I2.45 p.m. special demonstrations will be given; in the afternoon the post-graduates may attend surgical or medical in- or out-patients departments, or the special departments, or operations; from 4.30 to 5.30 a formal lecture will be given. The Course is open to men and women post-graduates, and is designed to appeal particularly to the general practitioner, both private and panel. The fee is $£ 33$ s. for the fortnight, or $£_{2}$ 2s. for either week. Luncheon and tea will be obtainable at the Hospital at a small charge. There will be daily pathological demonstrations, and Radium Therapy demonstration will be arranged. 